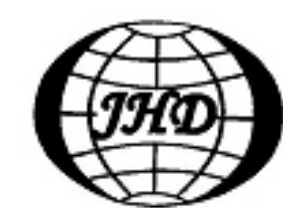

www.sciencedirect.com/ science/journal/10016058

\title{
PROCESS CONTROL OF THE SAND WAVE MIGRATION IN BEIBU GULF OF THE SOUTH CHINA SEA*
}

\author{
LI Yong, LIN Mian, JIANG Wen-bing \\ Institute of Mechanics, Chinese Academy of Sciences, Beijing 100190, China, E-mail: liyong@imech.ac.cn \\ FAN Feng-xin \\ Institute of Oceanology, Chinese Academy of Sciences, Qingdao, 266071, China
}

(Received December 26, 2010, Revised April 16, 2011)

\begin{abstract}
Based on the environment characteristics of the Beibu Gulf of South China Sea, a quasi-three-dimensional physical model is built. By coupling the bottom boundary layer with the two-dimensional tidal current field near the seabed surface, the quasi-three-dimensional hydrodynamic numerical simulation is carried out. The sand wave migration process is dealt with by coupling the hydrodynamic model with the sediment transport model. The computational results are shown to be in good agreement with the observed data, which indicates that the quasi-three-dimensional physical model can be used to simulate the migration process for small scale sand waves. Then, based on measured data, the evolution of the sand wave migration is investigated. An effective formula is developed to predict the migration rate, in which not only the effects of the environment but also the features of sand waves are considered.
\end{abstract}

Key words: small scale sand wave, sand wave migration, quasi-three-dimensional physical model, numerical simulation, in-situ measurement

\section{Introduction}

The Beibu Gulf area southwest to the Hainan Island is frequented with highly active sand waves, where are many pipelines for transporting oil and gas. The sand wave migration may create dangerous states under an abominable marine environment ${ }^{[1,2]}$. The migration of sand waves causes the exposure of the pipeline in the scour areas, which may result in an environmental disaster. Several accidents of pipeline free span due to the sand wave migration were reported in Beibu Gulf. Therefore, it is very important to study the process of the sand wave migration.

The sand wave migration, including the migration direction and rate, involves many complicated issues. Its study is mostly limited to theoretical ana-

* Project supported by the National Natural Science Foundation of China (Grant Nos. 11032007, 40576046).

Biography: LI Yong (1978-), Male, Ph. D.

Corresponding author: LIN Mian,

E-mail: linmian@imech.ac.cn lyses and numerical calculations based on empirical formula. Hulscher ${ }^{[3]}$ developed a model allowing for vertical circulation and described the initial evolution of the sand wave based on a horizontally averaged symmetrical tidal motion. In general, submarine sand waves are formed due to the ocean current transportation and the submarine sandy deposition. The steep slope points basically in the same direction as the preferential flow. Nemeth et al. ${ }^{[4]}$ developed a model describing the formation and the migration of sand waves in the infinite medium based on a stability analysis, with which the initial evolution and the migration of sand waves may find an explanation and where the periodic water motion $\left(\mathrm{M}_{2}\right)$ is taken into account in combination with the steady part $\left(\mathrm{M}_{0}\right)$. Besio et al. ${ }^{[5]}$ extended their model by including an $\mathrm{M}_{4}$ tidal constituent and the effect of the suspended sediment transport in a linear analysis. These models are basically semi-empirical and mainly applied to the sand waves with a long wavelength, which may be called the large scale sand waves.

In the Beibu Gulf area, the average wavelength of the sand wave is about $30 \mathrm{~m}$ and the sand waves 
belong to the category of small scale sand waves. Based on observation and theoretical analysis, Lin et al. ${ }^{[6]}$ studied the migration of the small scale sand waves, as dominant under the bed load in seas. The flow structures around small scale sand waves in river channels and coastal regions were also much studied. Raudikivi $^{[7]}$ investigated the flow pattern over the sand waves and measured the distribution of shear intensity and pressure. Lent coherent structures over single- and multi- sand waves were studied experimentally by $\mathrm{Liu}^{[8]}$. Liu et al. ${ }^{[9]}$ investigated the turbulent flow over sand waves by using the rapid distortion theory and the vertical two-dimensional Reynolds stress model was employed to simulate the turbulent flow around sand dunes in an alluvial river by Liu and $\mathrm{Yin}^{[10]}$. But so far there is not a multifield-coupled model reported to study the migration of small scale sand waves.

In the present article, a physical model for small scale sand waves is proposed. In view of the characteristics of the marine environment in Beibu Gulf, the tide and the wind-driven flows in the region southwest to the Hainan Island are simulated. The two-dimensional tidal current field near the seabed surface is coupled with the bottom boundary layer. In order to simulate the process of the sand wave migration, the quasi-three-dimensional flow is coupled with the sediment transportation. The measured data and the calculated results are used to analyze the migration process and a formula is developed to predict the migration rate.

\section{Numerical models}

\subsection{Governing equations}

For the purpose of investigating the sand wave migration in Dongfang, Beibu Gulf of the South China Sea, the tidal current field is first obtained. Based on the shallow water assumption, the governing equations for the tidal current can be derived from NavierStokes equations and they consist of the continuity equation and the momentum equation, as,

$$
\begin{aligned}
& \frac{\partial \xi}{\partial t}+\frac{\partial}{\partial x}(h u)+\frac{\partial}{\partial y}(h v)=0 \\
& \frac{\partial u}{\partial t}+u \frac{\partial u}{\partial x}+v \frac{\partial u}{\partial y}=f v-g \frac{\partial \xi}{\partial x}+\varepsilon \nabla^{2} u-\frac{1}{\rho h} \tau_{x}^{b} \\
& \frac{\partial v}{\partial t}+u \frac{\partial v}{\partial x}+v \frac{\partial v}{\partial y}=-f u-g \frac{\partial \xi}{\partial y}+\varepsilon \nabla^{2} v-\frac{1}{\rho h} \tau_{y}^{b}
\end{aligned}
$$

where $\xi$ is the free surface elevation, $h$ is the water depth, $u$ and $v$ are the velocity components in the longitude $(x-)$ and latitude $(y$-) directions, res- pectively, $g$ is the acceleration of gravity, $\mathcal{E}$ is the eddy viscosity, and $\tau_{x}^{b}$ and $\tau_{y}^{b}$ represent the shear stresses at the sea bottom in $x$ - and $y$-directions, respectively.

The bottom boundary layer is coupled with the two-dimensional tidal current field near the seabed surface, in the quasi-three-dimensional hydrodynamic numerical simulation.

In the bottom boundary layer, the wind-driven current is mainly considered, which is induced by the monsoon and plays an important role in the coastal hydrodynamics. In the Beibu Gulf, the wind direction mainly is NE-ENE in winter and S-SSE in summer. The mean wind speed is about $6 \mathrm{~m} / \mathrm{s}$ in winter and $5 \mathrm{~m} / \mathrm{s}$ in summer. In winter, the ocean current circulates counterclockwisely, as contrasted to that in summer.

In the present work, a wind-driven circulation model is adopted. In the bottom boundary layer, the velocity profiles are solved based on the law of the wall, as suggested by Csanady ${ }^{[11]}$,

$$
\begin{aligned}
& u(z)=\left[\frac{U_{*_{c}}}{\kappa} \ln \left(\frac{z}{k_{b}}\right)+8.5 U_{*_{c}}\right] \cos \gamma \\
& v(z)=\left[\frac{U_{*_{c}}}{\kappa} \ln \left(\frac{z}{k_{b}}\right)+8.5 U_{*_{c}}\right] \sin \gamma
\end{aligned}
$$

where $U_{*_{c}}=\sqrt{\tau_{c} / \rho_{f}}$ is the shear velocity at the top of the bottom boundary layer, $\rho_{f}$ denotes the density of water, $\kappa$ is the von Karman constant, $k_{b}$ is the physical bottom roughness, $\gamma$ denotes the direction of the slip velocity, $\tau_{c}=c_{d} R|R|$ is the bottom current shear stress, $c_{d}$ and $R$ are the friction coefficient and the bottom slip velocity, respectively.

For calculating the velocity field of the bottom boundary layer, Jeffries' derivation ${ }^{[11]}$ is used, where the bottom slip velocity is calculated through the wind speed $(Q)$ and direction $(\chi)$. The approach can be summarized as follows. First, an iteration is carried out to obtain the direction of the slip velocity,

$$
\begin{gathered}
{\left[\sqrt{\left.\frac{f \varepsilon\left(\rho_{f} \cos \chi \cos \gamma\right)}{\rho_{a} c_{d} c_{d s}}\right] \sin \gamma(\cosh 4 \lambda-\cos 4 \lambda)=}\right.} \\
2 Q \cos \gamma\left[\sin \left(\chi-\frac{\pi}{4}\right) \sinh 2 \lambda \cos 2 \lambda-\right. \\
\left.\cos \left(\chi-\frac{\pi}{4}\right) \cosh 2 \lambda \sin 2 \lambda\right]-
\end{gathered}
$$




$$
\begin{aligned}
& Q \cos \chi\left[\sin \left(\gamma-\frac{\pi}{4}\right) \sinh 4 \lambda-\right. \\
& \left.\cos \left(\gamma-\frac{\pi}{4}\right) \sin 4 \lambda\right]
\end{aligned}
$$

where $f$ is the Coriolis force, $\lambda=h \sqrt{f / 8 \varepsilon}, \rho_{a}$ represents the density of air, $c_{d s}$ is the friction coefficient at the water surface. by,

Then, the bottom slip velocity can be calculated

$$
R=\sqrt{\frac{\rho_{a}}{\rho_{f}} Q^{2} \frac{\cos \chi}{\cos \gamma} \frac{c_{d s}}{c_{d}}}
$$

In order to simulate the process of the sand wave migration, the sediment mathematical model is used to describe the sediment transportation and the bed deformation. The long-term migration processes can be simulated by coupling the sediment model with the quasi-three-dimensional hydrodynamic model with the tide and the wind-driven flow being both considered. The bed deformation equation adopted here can be written as,

$$
\begin{array}{r}
\frac{\partial \eta}{\partial t}+\frac{\partial}{\partial x}\left(q_{x}-\lambda_{m}\left|q_{x}\right| \frac{\partial \eta}{\partial x}\right)+ \\
\frac{\partial}{\partial y}\left(q_{y}-\lambda_{m}\left|q_{y}\right| \frac{\partial \eta}{\partial y}\right)=0
\end{array}
$$

where $\eta$ is the height of the sand wave, $\lambda_{m}$ denotes the sand wave slope, and $q$ is the volumetric sediment transport vector. The bed load transport is described by using Yalin's transport formula ${ }^{[11]}$,

$q_{b}=a_{1} u_{* b} S D\left[1-\frac{1}{a_{2} S} \ln \left(1+a_{2} S\right)\right]$

where $a_{1}=0.635, a_{2}=2.45\left(\rho_{f} / \rho_{s}\right)^{0.4}\left\{\tau_{\text {crit }} /\left[\left(\rho_{s}-\right.\right.\right.$ $\left.\left.\left.\rho_{f}\right) g D\right]\right\}^{0.5}, S=\left(\tau_{b}-\tau_{\text {crit }}\right) / \tau_{\text {crit }}, \quad \tau_{b}$ is the mean shear stress, $\tau_{\text {crit }}$ is the critical shear stress, $D$ is the sediment grain size, and $\rho_{s}$ is the density of sediment.

\subsection{Numerical implementation}

In the present study, the tidal current field for a large domain (including the whole Beibu Gulf area) is first simulated and the amplitude and the epoch of each grid node are obtained by harmonic analysis.
Then, the boundaries along a small research domain can be determined by interpolation and the tidal current velocity in the small concerned area can be calculated.

Galerkin Finite Element Method (FEM) is adopted to discretize the space domain of the hydrodynamic model, and the computational complexity is reduced by using the local mesh refinement method and being compared with the Finite Difference Method (FDM). As for the discretization of the temporal domain, the weighted FDM is employed,

$X_{i, j}=b_{1} X_{i, j}^{k-1}+b_{2} X_{i, j}^{k}+b_{3} X_{i, j}^{k+1}$

where $X_{i, j}$ is the spatial variable, superscript $k-1$, $k$ and $k+1$ denote time steps, and $b_{i=1,2,3}$ is the weight coefficient to adjust the numerical stability.

As for the boundaries of the large domain, at the land boundary, zero flux is given. The water level at the open boundary is obtained from the global tidal information and is represented by three major constituents, including $\mathrm{K}_{1}, \mathrm{O}_{1}$ and $\mathrm{M}_{2}{ }^{[12]}$. The water level can be expressed by,

$\zeta=\sum_{i=1,2,3} A_{i} \cos \left(\omega_{i} t-g_{i}\right)$

where $A_{i}$ is the amplitude of the partial tide, $\omega_{i}$ is the tidal frequency, and $g_{i}$ is the epoch of the partial tide. The cold start $(u=v=0 \mathrm{~m} / \mathrm{s})$ is taken as the initial condition. In order to satisfy the initial calm water condition, the velocity at the open boundary is increased gradually by using a modulation function. The modified velocity at the modulation period can be written as,

$u_{m}=\frac{1}{2}\left(1-\cos \frac{\pi t}{T_{m}}\right) u$

where $T_{m}$ is the modulation time.

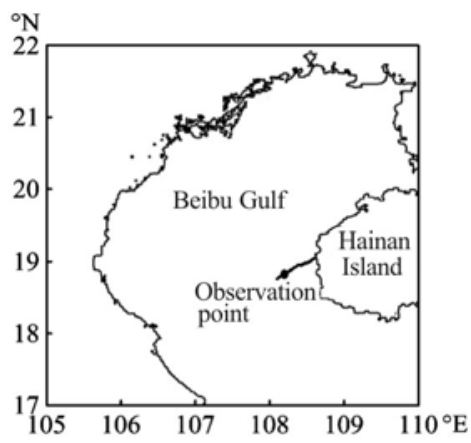

Fig.1 Location of the survey area 
FDM is also used to solve the two-dimensional bed deformation equation (Eq.(7)). The diffusion term is discretized by the central difference scheme with second-order accuracy and the forward difference scheme is employed for the time discretization.

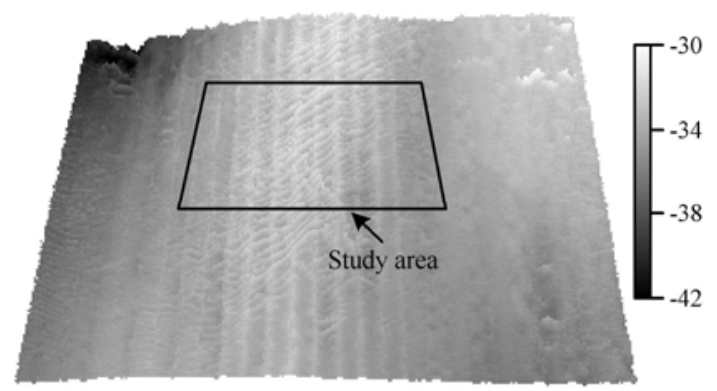

Fig.2 Bathymetric map of the sand wave area in 2004

\subsection{Model validation}

Submarine in-situ measurements for the area southwest to the Hainan Island were carried out in 2004 and 2005 by Institute of Oceanology, Chinese Academy of Sciences. Figure 1 shows the position of the observation point, which is located in the north latitude $18^{\circ} 52^{\prime}$, east longitude $108^{\circ} 17^{\prime}$. The mean water depth of this area is about $33 \mathrm{~m}$. The bathymetric map of the sand wave area in 2004 is shown in Fig.2. The present study area is selected according to the distribution of the sand waves and there are approximately twenty sand waves in this area, which are mainly distributed on the valley and the slope of the sand ridge. The mean wavelength is around $30 \mathrm{~m}$. The wave heights of sand waves are generally less than $1.5 \mathrm{~m}$ and the maximum wave height is no more than $3 \mathrm{~m}$. The sand waves belong to the category of small scale sand waves.

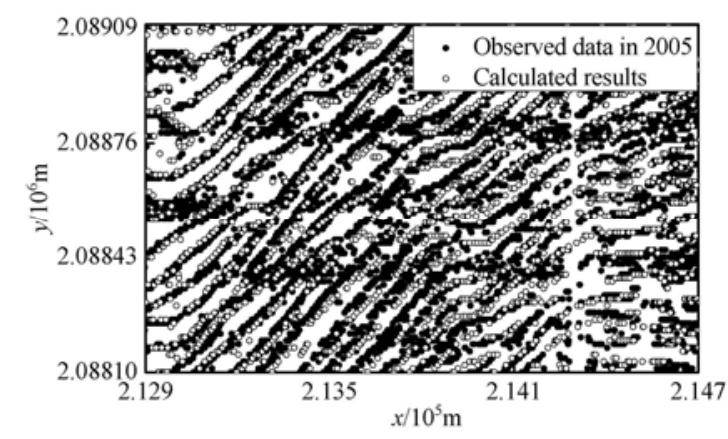

Fig.3 Comparison of wave crest line between observed data and calculated results

A comparison of the wave crest line between the observed data and the calculated results in 2005 is shown in Fig.3. They are in fairly good agreement on the valley and the slope of the sand ridge. It shows that the model structured for the small scale sand wave is reasonable. In addition, it can also be seen that an obvious difference exists between the observed data and the calculated results at the crest of the sand ridge. The deviation may be due to the motion of the typhoon. The bottom velocity induced by the typhoon is always more than $2 \mathrm{~m} / \mathrm{s}$. For the small scale sand wave, an obvious migration will occur under the effect of the typhoon and the migration rate will increase greatly under that extreme condition. It is shown that the migration rate of the small scale sand wave will be $7 \mathrm{~m} / \mathrm{h}$ and $11 \mathrm{~m} / \mathrm{h}$ in the typhoon condition with recurrence period of 1 year and 100 years, respectively. The field observations indicate that there are several typhoons every year which just pass through the Beibu Gulf. Actually, there were three typhoons passing through the study area from July 2004 to October 2005, named Damrey, Vicente and Washi, respectively.

\section{The analysis of sand wave migration}

\subsection{Symmetry index and steep ratio}

Since sand waves are widely distributed on the valley and the slope of sand ridges, and the wavelength, the wave height and the shape of sand waves at different positions in the research area are not the same, it is necessary to refine the study area. The locations and ranges of seven divided small regions are shown in Fig.4. Zones of A-F are on the valley of the sand ridge, while Zone $\mathrm{G}$ is on the crest.

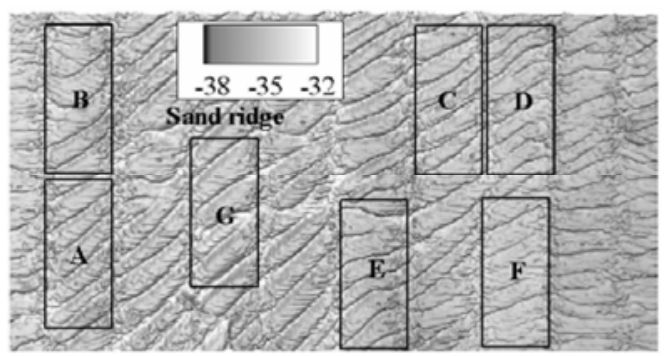

Fig.4 Seven small refined Regions (A-G)

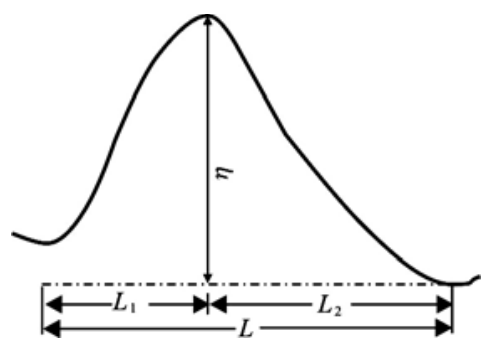

Fig.5 Definition of the sand wave characteristics

Knaapen $^{[13]}$ found a strong correlation between the sand wave shape and the migration rate, using a symmetry index to express the relationship between the migration direction and the sand wave asymmetry. 


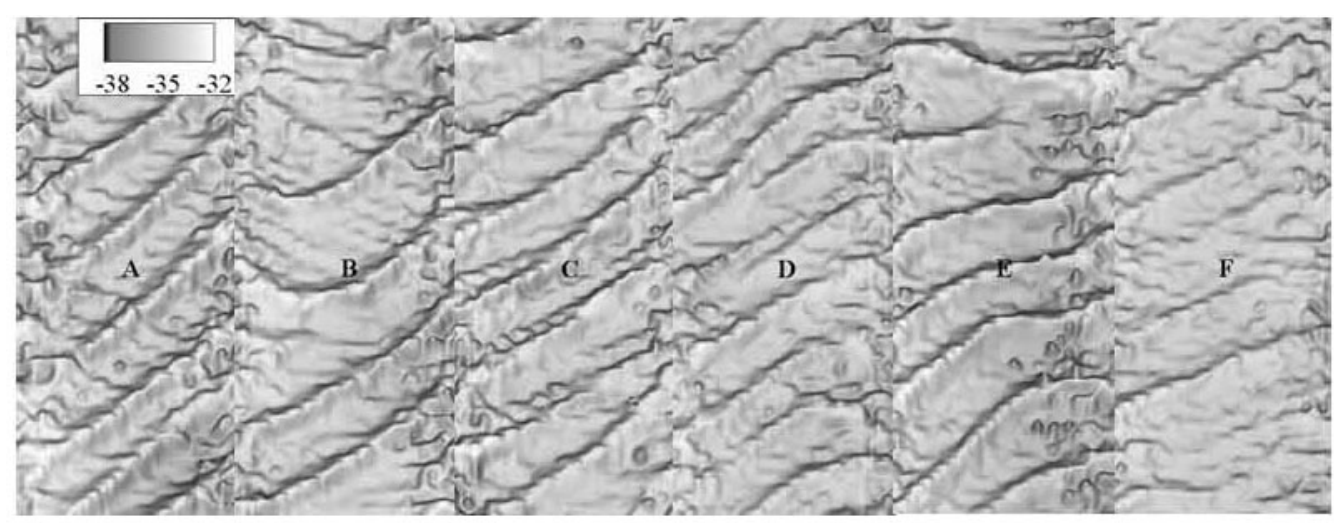

Fig.6 Bathymetric map of six refined zones

Table 1 Mean value of symmetry index and steep ratio

\begin{tabular}{ccccccc}
\hline Zone & $\mathrm{A}$ & $\mathrm{B}$ & $\mathrm{C}$ & $\mathrm{D}$ & $\mathrm{E}$ & $\mathrm{F}$ \\
\hline Water depth $(\mathrm{m})$ & 32.11 & 33.20 & 32.69 & 33.37 & 34.20 & 33.94 \\
$\mid$ Symmetry index $\mid$ & 0.364 & 0.311 & 0.325 & 0.289 & 0.209 & 0.281 \\
Steep ratio & 0.132 & 0.112 & 0.109 & 0.088 & 0.085 & 0.094 \\
\hline
\end{tabular}

In order to study the migration based on seven regions, in the present work, three indices are introduced to describe the shape of the sand waves: the symmetry index, defined as $\alpha=\left(L_{1}-L_{2}\right) / L$, the steep ratio, defined as $\beta=\max \left(\eta / L_{1}, \eta / L_{2}\right)$, and the relative wavelength, defined as $\zeta=L / h$, where $L$ is the wavelength of the sand wave, $\eta$ is the wave height, as illustrated in Fig.5.

Figure 6 shows the resulting bathymetry for the refined six Zones (A-F), from which the sand wave crests can be seen clearly. The sand wave migration rates are determined by the change of the crest position, as deduced from long time series of echo-sounding data.

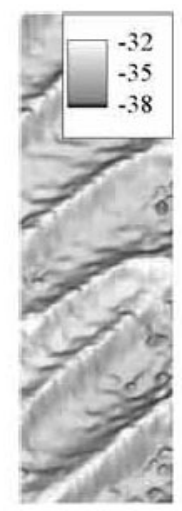

Fig.7 Bathymetric map of Zone G

Table 1 lists the mean values of $|\alpha|$ and $\beta$ for six zones. The value of the symmetry index ranges from $0.2-0.37$ and that calculated by Knaapen ${ }^{[13]}$ is from 0.0-0.6. From the table, it can also be seen that the mean value of the steep ratio is about 0.1 and the symmetry index and the steep ratio both decrease with the increase of the water depth.

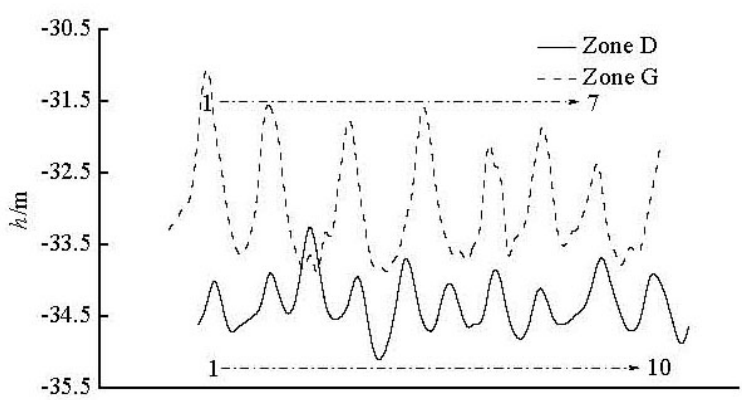

Fig. 8 Sand wave profiles

Figure 7 shows the bathymetry of Zone G, located on the crest of the sand ridge. Figure 8 shows the sand wave profiles parallel to the principal tidal current in Zone D and Zone G. There are ten sand waves in Zone D and seven in Zone G, which indicates that the mean wavelength of the sand waves on the crest is larger than that on the valley. Furthermore, the mean wave height of the sand waves in Zone G is also larger than that in Zone D.

Nemeth et al. ${ }^{[4]}$ suggested that the tidal asymmetry is responsible not only for the migration of sand waves, but also for the lee-stoss asymmetry, which is a sign for the migration in the direction of the steeper slope. Knaapen ${ }^{[13]}$ also found that the migration follows the same direction as that of the steepest slope. 
Figure 9 and Figure 10 show the distribution of the symmetry index and the steep ratio for the sand waves in Zones $D$ and $G$, respectively. It is seen that the mean symmetry index of the sand waves in Zone D are nearly all negative while those in Zone $\mathrm{G}$ are all positive. The measured data show that the direction of the migration on the crest of the sand ridge is opposite to that on the valley. Therefore, the sign of the symmetry index can indicate the direction of the migration.

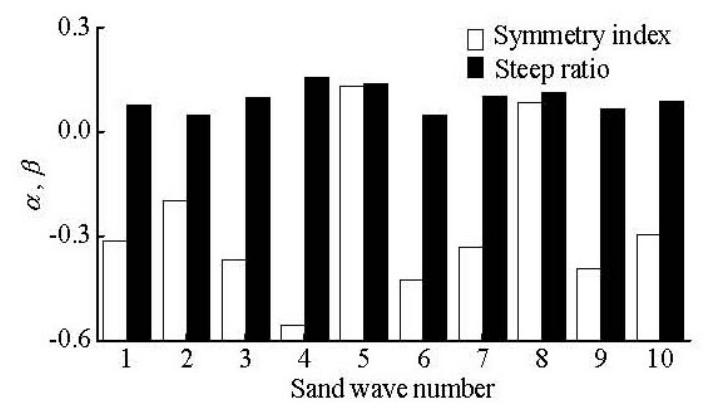

Fig.9 Distribution of symmetry index and steep ratio for sand waves in Zone D

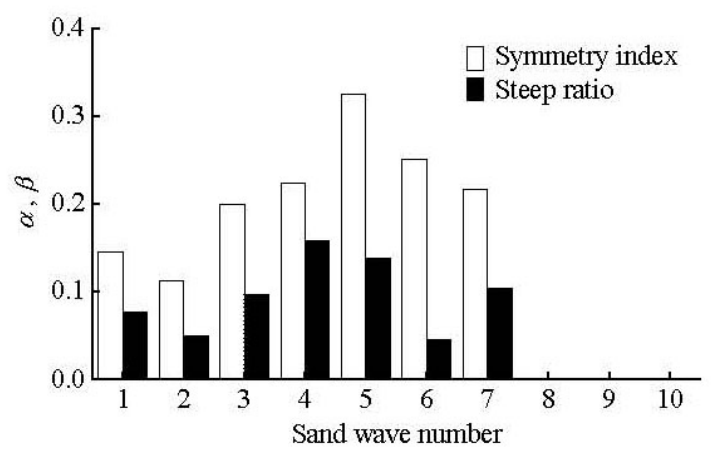

Fig.10 Distribution of symmetry index and steep ratio for sand waves in Zone $\mathrm{G}$

\subsection{Relations between the migration rate and various parameters}

The migration rate is generally closely related with the symmetry index, the depth of water, the steep ratio, and the wavelength. First, let us discuss the relationship between the sand wave migration rate and the symmetry index. Knaapen ${ }^{[13]}$ found that a linear function of the symmetry index gives a lower value than by a function of some power of the symmetry index and a squared function $\left(\alpha^{2}\right)$ gives the best fit. For the present study, the relation between the migration rate and the asymmetry is shown in Fig.11. It can be seen that the migration rate increases with the increase of the symmetry index and a nonlinear second order relationship between the migration rate and the symmetry index is found consistent with the fitting results. The migration rates of the sand waves in the study area are in the range of $8.5 \mathrm{~m} /$ year $-11.5 \mathrm{~m} /$ year, close to the observation result of $7 \mathrm{~m} /$ year for Ledong ${ }^{[14]}$, while much larger than $0.18 \mathrm{~m} /$ year $-1.99 \mathrm{~m} /$ year obtained by Xia et al. ${ }^{[15]}$ for Dongfang, based on a theoretical analysis.

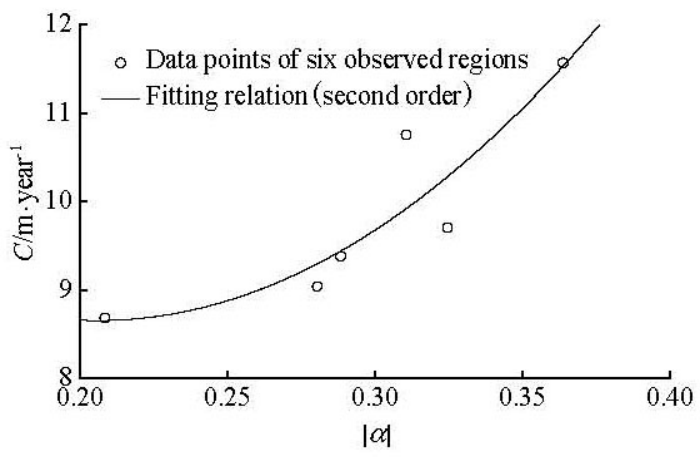

Fig.11 Relation between the migration rate and the symmetry index of the sand wave

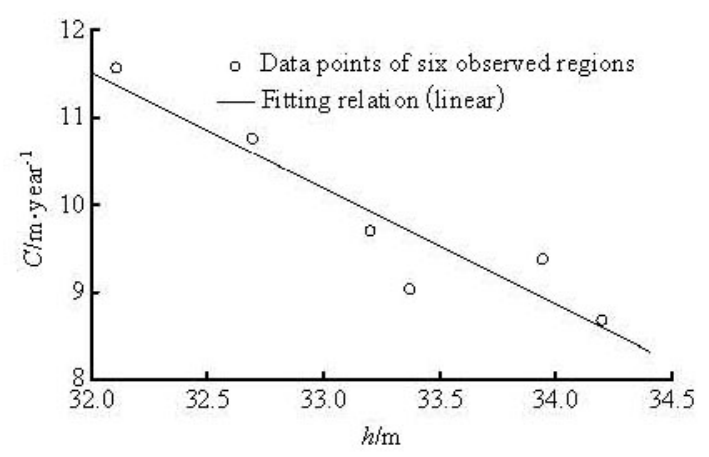

Fig.12 Relation between the migration rate and the depth of water

Secondly, we consider the relation between the migration rate and the water depth, as shown in Fig.12. The migration rates of the sand waves in the shallow water area are larger than those in the deep water region. The figure shows that the water depth has an important influence on the sand wave migration and there is a linear relationship between the migration rate and the water depth.

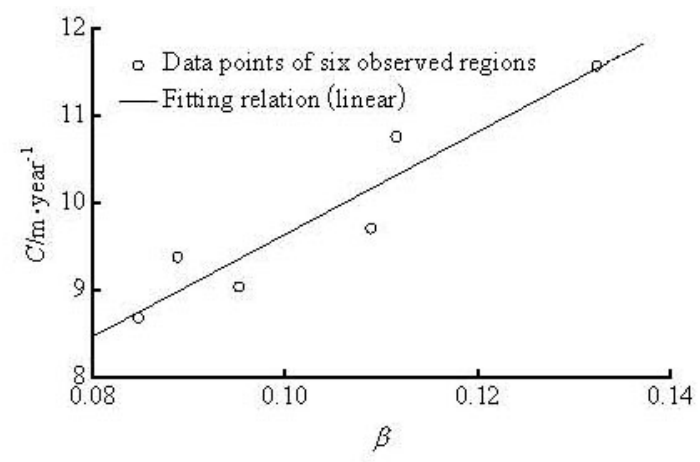

Fig.13 Relation between the migration rate and the steep ratio of the sand wave 
Then, we discuss the relation between the migration rate and the steep ratio. As shown in Fig.13, the steep ratios of various regions see a great difference, and the rates increase with the increase of the steep ratios. There exists a linear relationship between the migration rate and the steep ratio.

\subsection{A formula for migration rate}

Knaapen $^{[13]}$ analyzed the influence of various factors on the migration rate and based on some assumptions, a formula for the migration rate was obtained, which can be expressed as,

$$
c=\varphi L \frac{L}{h} \alpha|\alpha|
$$

where $\varphi$ is an undetermined coefficient. This formula is for the migration rate in the range of $0 \mathrm{~m} /$ year $-9 \mathrm{~m} /$ year, which is far below that of North Sea, as reported by Morelissen ${ }^{[1]}$. The rates calculated by above formula will be close to zero when the symmetry index is very small, which seems to agree with the observation on the Middelkerke sandbank in Southern North Sea ${ }^{[16,17]}$. Lanckneus et al. ${ }^{[16]}$ indicated that the sand waves can change their orientation at a seasonal time scale without showing significant migration. But in general, due to the effect of the residual current, the migration rate of the sand wave approaches almost to a constant in a long time scale.

In the present work, based on the analysis about the relations between the migration rate and various parameters, a new formula is proposed to calculate the sand-wave migration rate for Beibu Gulf

$c=\varphi_{1} \theta+\varphi_{2} \phi$

where $\theta$ is the shield number, $\theta=U^{2} /[(\gamma-1) g D]$, $\phi=\omega A \zeta \alpha^{2} \beta, \omega$ is the tidal frequency, $A$ embodies the influence of the wind-driven flow, $A=$ $0.535 Q^{2}, \varphi_{1}$ and $\varphi_{2}$ are undetermined coefficients, $\varphi_{1}=0.013, \varphi_{2}=0.86$. As mentioned before, the sign of the symmetry index can indicate the direction of the sand wave migration. Therefore, the final modified formula can be written as,

$c=\operatorname{SIG}(\alpha)\left(\varphi_{1} \theta+\varphi_{2} \phi\right)$

where $\operatorname{SIG}(\alpha)$ is a sign function. The first part of the formula represents the influence of the sediment grain size on the migration rate. The greater the grain size is, the greater the incipient velocity of the sediment is required, and the less migration rate will be. The second part of the formula represents the influence of the tide, the wind-driven flow, the sand wave shape, and others.

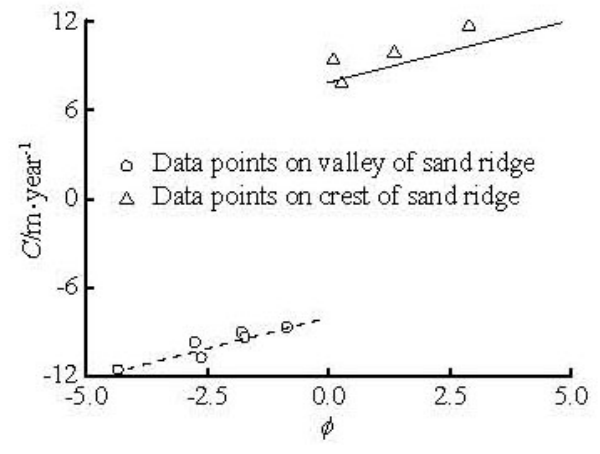

Fig.14 Comparison of migration rate between predicted rates and observed data

The values of the migration rate obtained from the observed data are plotted in Fig.14. It can be seen that the predicted results (dash line) agree well with the observed data in October 2005. Figure 14 also shows a comparison of the migration rate for the sand waves on the crest of the ridge (solid line). Four zones are selected on the crest of the ridge in the study region, as shown in Fig.15. The results indicate that Eq.(14) can be used to roughly predict the migration rates of the sand waves on the crest of the ridge.

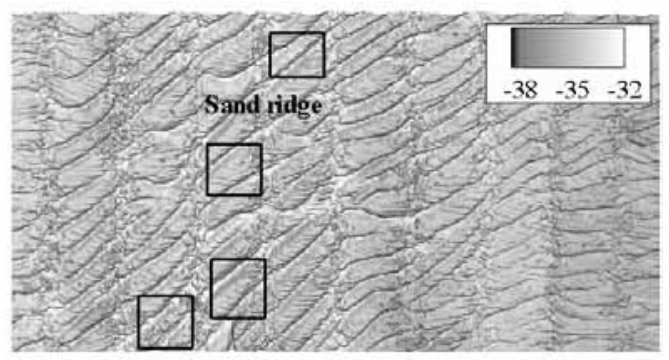

Fig.15 Sand wave zones selected on the crest of ridge

\section{Conclusion}

In the present article, the quasi-three-dimensional hydrodynamic model is coupled with the sediment transport model and the migration process of the sand waves in the Beibu Gulf of the South China Sea is simulated. Observed data and calculated results are basically in agreement, which shows that the multifield-coupling model can be used to simulate the sand wave migration in actual sea areas. The relationships between the migration rate and the symmetry index, the steep ratio and the water depth are discussed. The results show that the migration rate and the symmetry index follow a nonlinear second order relation, and there is a linear relationship between the rate and the steep ratio, also between the rate and the water depth. The greater the steep ratio is, the greater the migration rate is. However, the rate decreases with the increase of the water depth. A new formula for the migration 
rate is obtained, with consideration of various factors, such as the tide and wind-driven flows, the shape of the sandwave, and the sediment grain size. The formula can well characterize the features of the sand wave migration in the Beibu Gulf of the South China Sea.

\section{References}

[1] MORELISSEN R. S. J. M. H., HULSEHER M. A. F. and KNAAPEN A. A. Mathematical modelling of sand wave migration and the interaction with pipelines[J]. Coastal Engineering, 2003, 48(3): 197-209.

[2] DONG Zhi-hua, CAO Li-hua and XUE Rong-jun. The influence on topography and relief in South Gulf Beibu and suspending of pipe caused by Typhoon[J]. Ocean Technology, 2004, 23(2): 24-34(in Chinese).

[3] HULSCHER S. J. M. H. Tidal induced large-scale regular bed form patterns in a three-dimensional shallow water model[J]. Journal of Geophysical Research, 1996, 101(C9): 20727-20744.

[4] NEMETH A. A., HULSCHER S. J. M. H. and DE VRIEND H. J. Modelling sand wave migration in shallow seas[J]. Continental Shelf Research, 2002, 22(18-19): 2795-2806.

[5] BESIO G., BLONDEAUX P. and BROCCHINI M. et al. On the modeling of sand wave migration[J]. Journal of Geophysical Research, 2004, 109(C4): C04018.

[6] LIN Mian, FAN Feng-xin and LI Yong et al. Observation and theoretical analysis for the sand-waves migration in the North Gulf of South China Sea[J]. Chinese Journal of Geophysis, 2009, 52(3): 776-784(in Chinese).

[7] RAUDIKIVI A. J. Loose boundary hydraulics[M]. 2nd ed., Oxford, UK: Pergamon Press, 1976.

[8] LIU Shi-he. Turbulent coherent structures in channels with sand waves[J]. Journal of Hydrodynamics, Ser. B, 2001, 13(2): 106-110.
[9] LIU Shi-he, XIONG Xiao-yuan and LUO Qiu-shi. Theoretical analysis and numerical simulation of turbulent flow around sand waves and san bars[J]. Journal of Hydrodynamics, 2009, 21(2): 292-298.

[10] LIU Shi-he, YIN Shu-ran. Turbulent flows around sand dunes in alluvial rivers[J]. Journal of Hydrodynamics, 2010, 22(1): 103-109.

[11] COOKMAN J., FLEMINGS P. B. STORMSED1.0: hydrodynamics and sediment transport in a 2-D, steadystate, wind- and wave-driven coastal circulation model[J]. Computers and Geosciences, 2001, 27(6): 647-674.

[12] ZHAO Chang, LU Xin-gang and QIAO Fang-li. Numerical study of the tidal waves in the Gulf of Tonkin[J]. Acta Oceanologica Sinica, 2010, 32(4): 1-11(in Chinese)

[13] KNAAPEN M. A. F. Sandwave migration predictor based on shape information[J]. Journal of Geophysical Research, 2005, 110(F4): F04S11.

[14] WANG Lin, WU Jiang-zheng and SHI Wei. Research on the shape character and activity of submarine sand waves of Ledong, Hainan Island[J]. Transactions of Oceanology and Limnology, 2007, (Suppl.): 53-59(in Chinese).

[15] XIA Dong-xing, WU Sang-yun and LIU Zhen-xia. Research on the activity of submarine sand waves of Dongfang, Hainan Island[J]. Journal of Oceanography of Huanghai and Bohai Seas, 2001, 19(1): 17-24(in Chinese).

[16] LANCKNEUS J., DE MOOR G. and STOLK A. Environmental setting, morphology and the volumetric evolution of the Middelkerke Bank (Southern North Sea) [J] Marine Geology, 1994, 121(1-2): 1-21.

[17] LANCKNEUS J., DE MOOR G. Bedforms on the Middelkerke Bank, southern North Sea[J]. Spec. Publs. int. Ass. Sediment, 1995, 24: 33-51. 